\title{
Focalizando um segmento específico da rede privada de ensino: escolas particulares de baixo custo
}

\author{
Ana Rita Siqueira' \\ Maria Alice de Lima Gomes Nogueira'
}

\section{Resumo}

Com base nos dados do censo escolar do Inep/MEC, este artigo parte da constatação empírica de que, no Brasil da última década, temos assistido a uma expansão contínua da matrícula na escola particular no nível da educação básica, fenômeno que, ao que tudo indica, estaria relacionado com a melhoria das condições econômicas de uma parcela das classes populares no país. No entanto, a literatura sociológica se volta principalmente para aquele segmento da rede privada de ensino que acolhe majoritariamente uma clientela formada pelas elites e pelas frações mais favorecidas das classes médias, desconhecendo a heterogeneidade interna existente no universo mais amplo das instituições privadas, notadamente aquelas que oferecem mensalidades de custo mais baixo e que, portanto, recrutam famílias provenientes de estratos sociais menos abastados. 0 objetivo da pesquisa foi dar os primeiros passos no sentido de conhecer as características desse segmento da rede particular de ensino. Para tanto, foram investigados dois estabelecimentos de ensino privados da cidade de Contagem, em Minas Gerais. A seleção das escolas foi feita a partir da mensalidade cobrada. 0s instrumentos de pesquisa utilizados foram a observação direta do funcionamento do estabelecimento e a entrevista semiestruturada com profissionais da escola e com famílias usuárias. Os resultados evidenciaram a existência de algumas características comuns aos dois casos investigados, a saber: origem e gestão familiares; estrutura física e patrimônio material e pedagógico restritos; recursos humanos marcados pela multifuncionalidade; cuidados especiais com a disciplina e segurança dos alunos; proximidade na interação família-escola.

I- Universidade Federal de Minas Grais, Belo Horizonte, MG, Brasil.

\section{Palavras-chave}

Escola particular - Nova classe média - Rede privada de ensino. 


\title{
Focusing on a specific segment of the private education system: low-cost private schools
}

\author{
Ana Rita Siqueiral \\ Maria Alice de Lima Gomes Nogueira'
}

\begin{abstract}
Based on the school census data of Inep/MEC, this article focuses on empirical finding that, over the last decade in Brazil, a continuous expansion of enrollment has been seen in private schools of basic education. Evidence has shown that this phenomenon is related to the improvement of economic conditions of certain part of Brazilian low-income classes. However, sociological literature has been looking mainly at a clientele composed by the elites and wealthier fractions of middle-classes, ignoring the internal heterogeneity of the broader sector of private institutions, especially those which offer low-cost tuitions therefore attracting families from lower-income fractions. The objective of the research was to take the first steps to understand the characteristics of this private education segment. To do so, we investigated two private schools in the city of Contagem, Minas Gerais. We selected the schools based on the tuition value. The research instruments were the direct observation of the school and semi-structured interviews with school professionals and families. The results have shown some shared characteristics of the two cases investigated: origin and family management; limited facilities and material and pedagogical assets; human resources engaged in multitasking; special care with students' discipline and safety; close family-school interaction.
\end{abstract}

\section{Keywords}

Private school - New middle class - Private school system.

I- Universidade Federal de Minas Grais, Belo 


\section{Introdução}

É fato notório que, desde a década de 1990, o Brasil vem passando por um amplo processo de democratização do acesso à educação básica, em particular com a universalização do ensino fundamental e com o crescimento expressivo da matrícula no ensino médio. Se é certo que esse processo se deu principalmente pela via da ampliação das redes estaduais e municipais de ensino, tal tarefa foi facilitada pela transição demográfica por que passa o país, com a gradual redução de sua população em idade escolar.

Completando esse cenário, estamos assistindo a uma gradual expansão da rede privada de ensino básico, como evidenciam os dados dos censos escolares do Inep/MEC, de 2003 a 2013, que mostram um crescimento de $12 \%$ para $17 \%$ das matrículas nas escolas particulares de educação básica do país1. Esse último fenômeno ainda está cercado por grande desconhecimento, dada a crônica falta de dados e de pesquisas sobre o ensino privado brasileiro no nível da educação básica, em que pesem algumas tentativas de tornar mais conhecida essa nova realidade educacional. Em particular, três estudos feitos por pesquisadores paulistas, embora baseados em estatísticas relativas ao estado ou à cidade de São Paulo, fornecem pistas relevantes para o que se passa em outras regiões do país.

Partindo da constatação de que o crescimento recente do setor privado vem se dando em todos os níveis de ensino, tais estudos detectam que ele ocorre com mais força (i.e., "de forma vigorosa e contínua") nas séries iniciais do ensino fundamental (MEDEIROS; JANUÁRIO, 2014, p. 1). A segunda constatação dos pesquisadores é que a expansão da rede particular está se dando entre as famílias mais pobres que estariam se beneficiando de um processo de ascensão econômica.

Com efeito, Camelo (2014, p. 12) verifica uma modificação no perfil dos usuários da escola

1 - Além da matrícula, o setor privado exibiu ainda, entre 2002 e 2013, um aumento de $8,8 \%$ no número de estabelecimentos de ensino, enquanto a oferta de escolas públicas decresceu $13 \%$. privada, pois, entre 2002 e 2012, a "participação do ensino privado entre as famílias mais pobres [com renda familiar per capita de até 2 salários mínimos] mais que dobrou, de $8,4 \%$ a $18,1 \%$ " no ensino fundamental, ao passo que "o crescimento nos demais segmentos foi relativamente menor". Mas ele reconhece que a escolaridade dos pais dos alunos do setor privado permanece bem mais elevada do que a das famílias que se servem da rede pública de ensino:

Nas escolas privadas, em 2012, 43,1\% e $40,4 \%$ dos alunos tinham, respectivamente, pai e mãe com ao menos ensino médio completo e quase metade com superior completo. 0 contrário acontece com os pais de alunos de escolas públicas, em que não chega a 7\% a proporção de pais e mães com ensino superior completo. (CAMELO, 2014, p. 13).

Por fim, ao examinar dados relativos ao estado de São Paulo, Camelo (2014) verifica que a expansão da escola particular é maior nas cidades mais populosas (com mais de 500 mil habitantes) e mais ricas (com renda per capita superior a mil reais), onde a participação relativa da matrícula privada se eleva a mais de 20\% dos efetivos escolares. Ainda segundo ele, essa expansão não se deve a uma incapacidade dos poderes públicos de satisfazer à demanda por escolarização (com exceção do ensino infantil que apresenta uma situação particular). Para ele, a razão principal tem a ver com a preferência das famílias pela escola particular, que as leva a migrar para essa rede de ensino que consideram superior em vários aspectos: resultados escolares, infraestrutura, organização e índices de violência.

Nesse sentido e face à ausência de dados sobre as condições dos estabelecimentos de ensino privados que abrigam essa nova população escolar, o autor formulou - e comprovou - a hipótese de que a opção das famílias pelo setor privado seria maior em municípios com baixo Ideb (Índice de Desenvolvimento da Educação 
Básica), onde supostamente é mais baixa a qualidade das escolas públicas.

Verifica-se que, entre os municípios paulistas com Ideb (anos iniciais do EF) até 5,0, o share das escolas privadas aumentou mais de 5 p.p., enquanto entre aqueles com Ideb acima de 6,0 tal ampliação não passou de 3,5 p.p. no ensino fundamental e 3,9 p.p. no médio. Usando como parâmetro o Ideb dos anos finais do ensino fundamental, observa-se a mesma relação (CAMELO, 2014, p. 11).

Em sintese, segundo os estudiosos, "o ensino privado tornou-se mais acessível [...]. E este não é um fenômeno isolado ou mesmo passageiro" (CAMELO, 2014, p. 13-15). Considerando esse contexto histórico, uma dissertação de mestrado (SIQUEIRA, 2016) se propôs a reduzir o desconhecimento que cerca esse segmento da rede particular de ensino que vem se expandindo ao recrutar famílias pertencentes a estratos sociais de menor renda e, em grande parte, migrantes da escola pública, às quais oferecem uma escolarização privada de custo mais baixo em relação aos colégios particulares de alta reputação que atendem às elites e frações superiores das classes médias, cujo poder de consumo as classifica como classes A e B, segundo os termos utilizados pela pesquisa de mercado.

Este artigo retoma parte dos dados e das análises presentes nessa dissertação, que, no ano de 2015, investigou dois estabelecimentos privados de ensino fundamental e médio da cidade de Contagem, em Minas Gerais² . Os instrumentos utilizados na pesquisa foram: (i) a observação direta do funcionamento cotidiano das duas escolas por um período de quatro meses letivos (à razão de três dias por semana e de quatro horas por dia); (ii) entrevistas semiestruturadas com doze profissionais do ensino: quatro proprietárias/

2- Compondo a região metropolitana de Belo Horizonte, Contagem contribui com a terceira posição no PIB estadual. Foi determinante para sua escolha como terreno da pesquisa o fato de que, entre 2007 e 2014, o município apresentou uma taxa elevada de crescimento da matrícula na rede privada de ensino, da ordem de 29,6\% no EF I (séries iniciais) e 28,4\% no EF II (séries finais). membros da direção, duas coordenadoras pedagógicas, três professores, uma secretária, dois funcionários (portaria e cantina/faxina); (iii) entrevistas com oito mães e um pai de aluno; (iv) questionário de caracterização socioeconômica aplicado aos alunos.

\section{A Escola Joséz}

A história da escola José está intimamente associada à história e trajetória social da família de suas proprietárias. 0 estabelecimento iniciou suas atividades em 1993, a partir da iniciativa conjunta de quatro irmãs. Conceição, Clara, Ruth e Inês são oriundas de uma família pertencente às camadas populares, com recursos insuficientes para garantir a elas uma formação escolar longa. Provenientes do interior do estado de Minas Gerais, seus pais não foram além dos estudos primários, apesar de um início de carreira eclesial por parte do pai, que acabou por abandonar o seminário para se casar. Após a união, o casal mudou-se para o município de Contagem onde o pai trabalhou como jardineiro e a mãe como empregada doméstica. Todos os sete filhos tiveram que conciliar os estudos com a entrada precoce no mundo do trabalho.

Por volta dos 12 anos, Conceição, Ruth e Inês tornaram-se empregadas domésticas e assim permaneceram por mais de uma década. Clara, por ser a caçula, pode eximir-se dessa ocupação, atuando como ajudante em uma oficina de costura. Durante esse período, as irmãs tentavam perseverar nos estudos, prejudicados pelas longas jornadas de trabalho. Mas graças à figura do pai, que incentivava a continuidade da formação, as quatro irmãs concluíram o ensino médio e, posteriormente, o curso de magistério, o que lhes permitiu ingressar no ofício da educação. Inês, hoje secretária da escola, assim relembra esse passado:

[...] meu pai antes de ele casar com minha mãe, ele era seminarista, então ele tinha assim aquela doutrina voltada pra educação.

3- Por razões deontológicas, os nomes de instituições de ensino e de pessoas aqui fornecidos são fictícios. 
Então assim, quando ele era vivo a única preocupação dele conosco era que a gente estudasse, que a gente formasse, que a gente seguisse uma profissão, porque até então a gente estudava e trabalhava. É lógico, quem pagava o estudo da gente, que meu pai na época não tinha condições, era nós mesmo.

Após alguns anos trabalhando como professoras em diversos estabelecimentos de ensino, as irmãs começaram a ministrar na cozinha da própria casa aulas particulares para alunos da vizinhança em dificuldade escolar. Ao observar o número crescente de alunos que frequentavam a cozinha, o irmão, Francisco, reuniu a família e lançou a ideia de abrirem uma escola. As irmãs ouviram a proposta com cautela, preocupadas tanto com o espaço físico, quanto com os procedimentos legais necessários, sem, no entanto, fechar-se para as possibilidades do empreendimento. Ocorre que Francisco trabalhava no setor de manutenção de um grande colégio privado da cidade ${ }^{4}$, tendo se oferecido para ajudar na parte de infraestrutura e do espaço físico do novo estabelecimento de ensino. Coincidentemente, o vizinho da família acabava de se mudar e desejava alugar sua residência. Uma vez negociado o aluguel, as reformas estruturais começaram.

Contudo, as irmãs não se sentiam seguras quanto aos procedimentos burocráticos a encetar, em particular, a elaboração da documentação de natureza pedagógica. Francisco recorreu ao então diretor do Colégio São Judas Tadeu, que incentivou a iniciativa e disponibilizou o regimento interno e o projeto pedagógico do colégio como fonte de inspiração; sem falar no fato de que sua esposa (pedagoga) ofereceu consultoria pedagógica gratuita às novas proprietárias. Além disso, o colégio forneceu, durante anos, móveis como carteiras, mesas, armários e algum material didático para a Escola José. Ainda hoje, sempre

4- Trata-se de um tradicional colégio confessional, aqui denominado Colégio São Judas Tadeu. que o Colégio São Judas Tadeu renova seus móveis, os antigos são oferecidos à Escola José.

Durante quase uma década, a escola atendeu apenas os três níveis da educação infantil. Em 2002, as proprietárias decidiram dar início ao ensino fundamental (séries iniciais) 5 . A partir de 2006, como os pais passaram a solicitar a oferta das séries finais do EF, isso passou a ser feito gradativamente. Finalmente, em 2010, e mais uma vez cedendo à demanda da clientela, as irmãs deram início à oferta do ensino médio. Atualmente, a Escola José recebe setecentos alunos no total, distribuídos em salas de aula que contam, em média, com 25 alunos.

0 crescimento e a prosperidade do empreendimento levaram a uma ampliação gradual do espaço físico e à compra do imóvel pertencente ao antigo vizinho. Concomitantemente, as proprietárias adquiriram uma frota de vans para atender aos alunos moradores de bairros mais distantes.

Imagem 1 - Fachada da escola e parte da frota de vans.

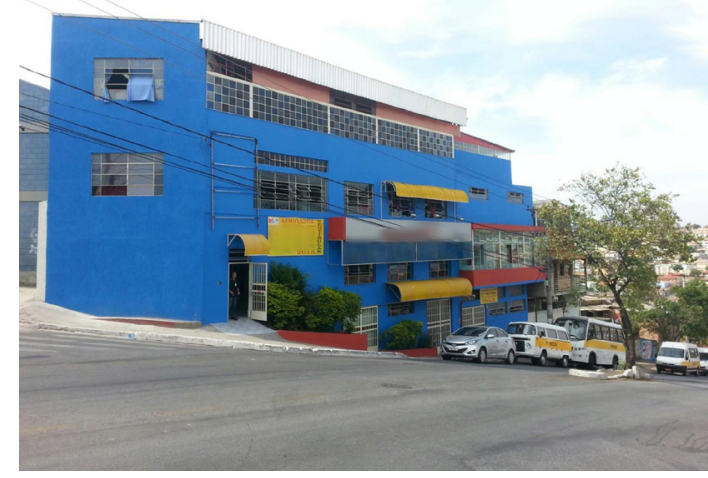

Fonte: arquivo pessoal da pesquisadora.

Concebido originalmente para ser uma residência familiar, o prédio da escola foi sendo, ao longo de 23 anos, submetido às adaptações necessárias para receber salas de aula e equipamentos escolares. Como o terreno

5- No momento de sua abertura, a escola levava um nome diferente daquele que tem hoje. Ocorre que, em 2002, com a abertura do EF I, as irmãs decidiram homenagear o pai, então falecido, conferindo à escola 0 seu nome. Daí nossa escolha pelo nome fictício de Escola José. 
não é muito amplo, a edificação resultou em um prédio estreito, porém em permanente crescimento vertical. Atualmente, o imóvel possui quatro andares, sendo que persiste a intenção de realizar novas obras, sempre sob a supervisão do irmão Francisco.

As imagens revelam um prédio que não ostenta a arquitetura própria de uma instituição de ensino. Como se vê na Imagem 1, na fachada há dois cartazes exibindo o nome dos alunos aprovados nos últimos vestibulares. Esse é o maior investimento da escola em matéria de publicidade e constitui - juntamente com a frota de vans estacionadas em frente ao imóvel - o único sinal externo de que uma instituição de ensino funciona no local.

Circular pelo imóvel evidencia o caráter de improviso da construção: a localização das escadas e de cada ambiente é pouco convencional, sinalizando uma edificação não planejada em seu ponto de partida. No interior da sala de reprografia, de acesso restrito, há uma porta que liga o prédio da escola à casa das proprietárias, situada no terreno contíguo: "elas [as proprietárias] têm uma porta aberta que eu descobri não tem muito tempo... que, de dentro da casa delas, elas caem aqui" (coordenadora pedagógica do ensino médio).

No edifício, há pouca incidência de luz natural. As áreas de convívio são em sua maioria cobertas, excetuando-se o pátio do ensino infantil e o acesso à quadra de esportes, que recebem diretamente a luz do sol.

Imagem 2 - Pátio do ensino infantil.

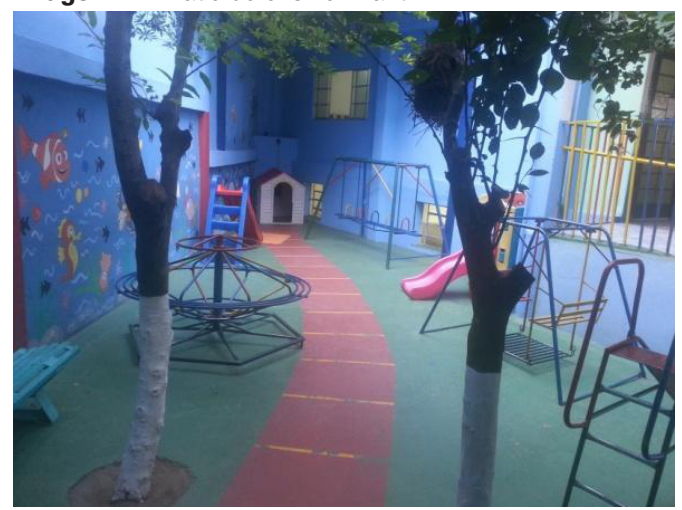

Fonte: arquivo pessoal da pesquisadora.
Imagem 3 - Quadra de esportes.

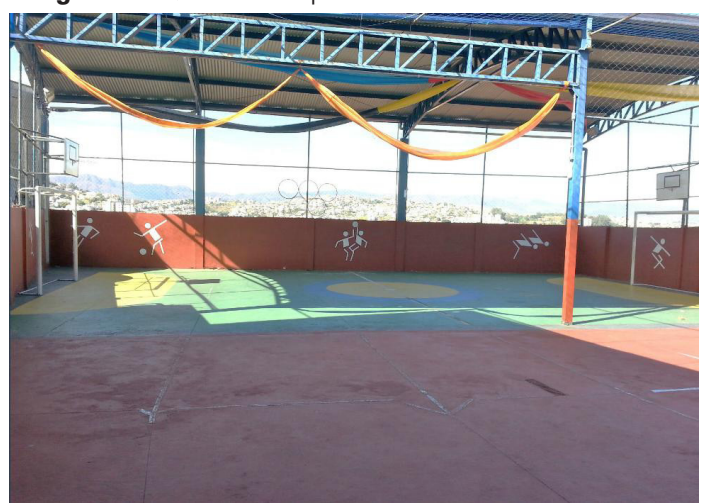

Fonte: arquivo pessoal da pesquisadora.

Os recursos da escola não se destinam à estética do imóvel: pisos e revestimentos são escolhidos para garantir praticidade e facilitar a limpeza. A manutenção é feita periodicamente. No entanto, grande parte dos móveis são frutos de doação e a instituição adapta suas práticas pedagógicas ao material existente, ao invés de se munir dos equipamentos necessários a metodologias de ensino previamente definidas.

Imagem 4 - Sala de aula do $7^{\circ}$ ano do EF.

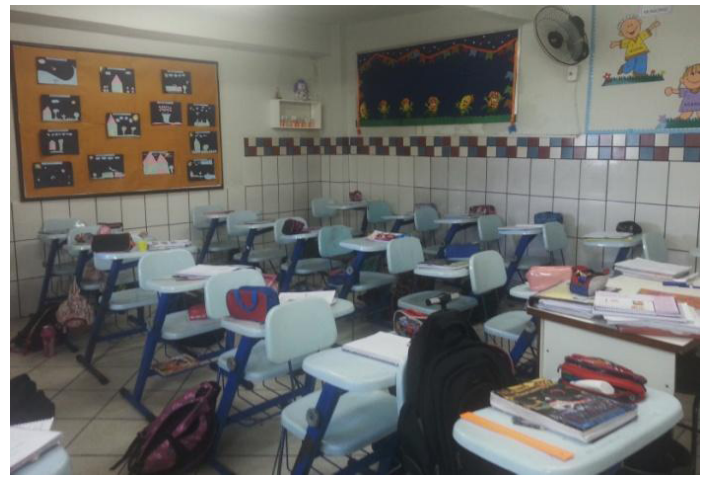

Fonte: arquivo pessoal da pesquisadora.

As salas de aula da Escola José têm tamanho reduzido, se comparado ao das grandes escolas privadas. 0 laboratório de informática possui onze computadores com acesso à internet e em bom estado de uso, segundo as proprietárias.

A biblioteca possui um acervo reduzido e, segundo a coordenadora pedagógica, é pouco 
Imagem 5 - Laboratório de informática.

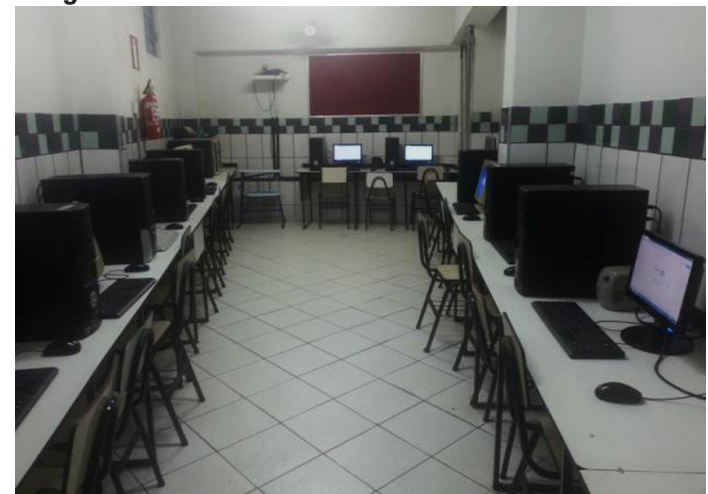

Fonte: arquivo pessoal da pesquisadora.

Imagem 6 - Laboratório de ciências.

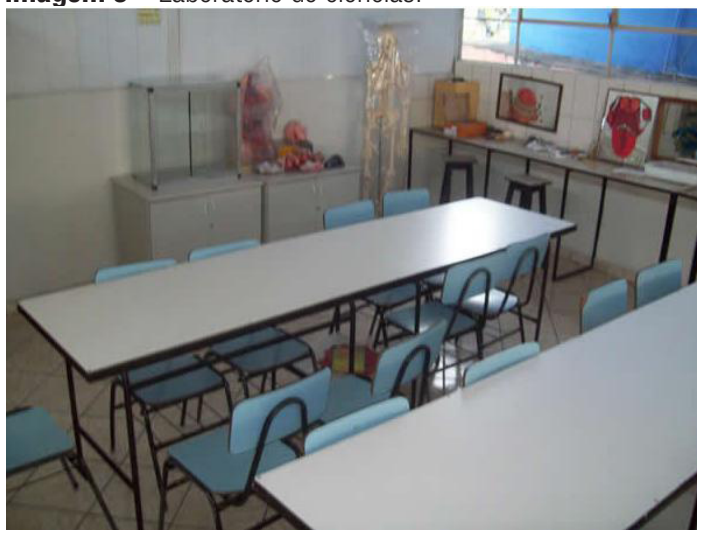

Fonte: site da instituição de ensino.

visitada pelos alunos, não constituindo um ambiente muito valorizado pela instituição.

Imagem 7 - Biblioteca.

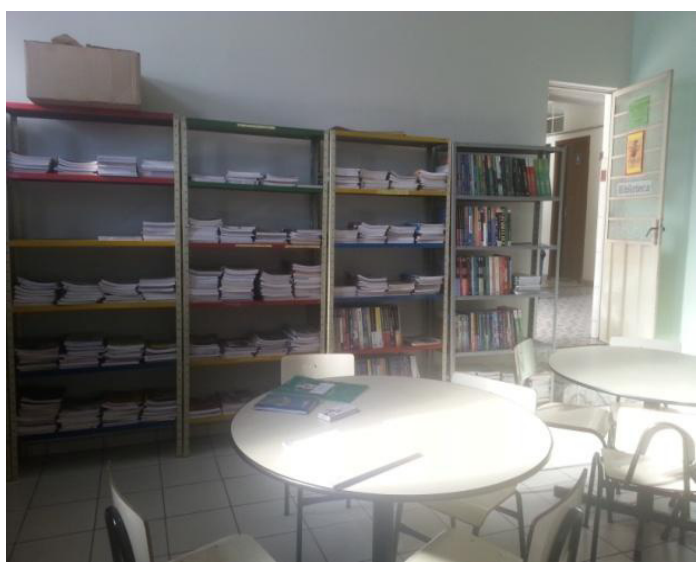

Fonte: arquivo pessoal da pesquisadora.
Na Imagem 8 da recepção (e acesso à secretaria, à esquerda), vê-se o detalhe de um crucifixo que atesta a religiosidade implícita no cotidiano da escola (e constatada durante a pesquisa de campo), apesar de a instituição se declarar laica ${ }^{6}$.

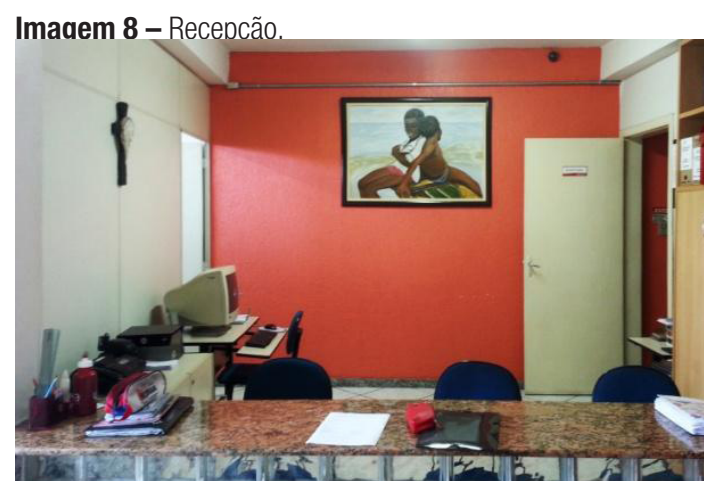

Fonte: arquivo pessoal da pesquisadora.

A cantina da Escola José é administrada por uma irmã das proprietárias, mas que não é sócia da empresa educacional.

\section{Imagem 9 - Refeitório.}

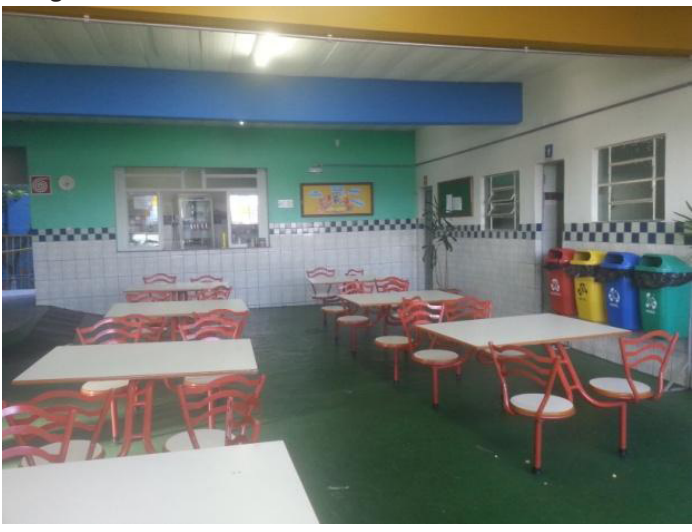

Fonte: arquivo pessoal da pesquisadora.

Ao lado da cantina há um espaço de lazer usado para o recreio dos alunos. Observa-se que não há um grande investimento nos espaços de convívio dos alunos fora da sala de aula.

6- "Elas [as proprietárias] têm uma Nossa Senhora deste tamanho [gesto] mas dentro da secretaria, lá no cantinho, ninguém sabe. Vela acessa todo dia, mas ninguém sabe", declara uma das coordenadoras pedagógicas. 
Imagem 10 - Pátio adjacente ao refeitório.

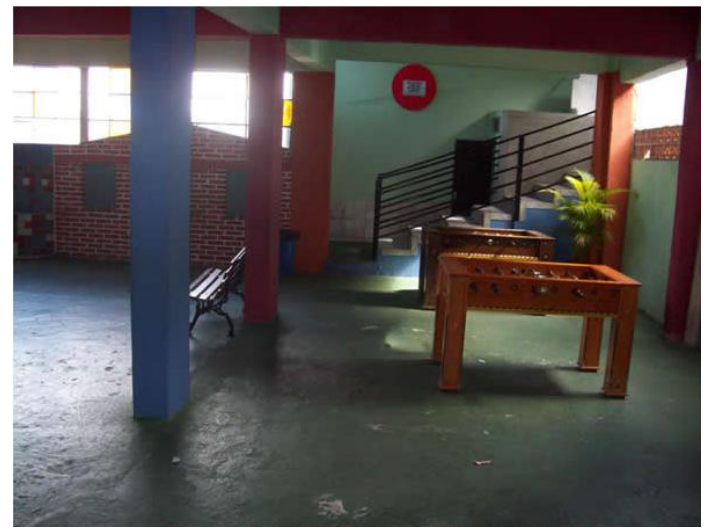

Fonte: site da instituição de ensino.

A fim de driblar as dificuldades causadas pela infraestrutura acanhada da escola para fazer face aos três níveis do ensino básico, os educadores recorrem ao improviso:

Tem uma sala de vídeo que a gente faz de auditório [...]. Eu trago muitas universidades para fazer palestra aqui, então agora eu arranjei um jeito [...]. No último andar tem aquela área grande na frente das salas, né? Aí eu arranjei um pano imenso, a gente estende aquele pano naquele vidro de fora a fora. Coloquei uns ganchinhos, né? Colocamos o datashow lá. Ficou escuro e um auditório maior que a sala de vídeo (coordenadora pedagógica do EM).

O site da Escola José informa que a metodologia de ensino praticada pela instituição se baseia na abordagem construtivista. No entanto, os entrevistados relataram uma grande autonomia deixada aos professores no desenvolvimento de suas atividades em sala de aula, segundo as características da turma e dos conteúdos curriculares. 0 material didático utilizado também é definido em acordo com os professores (e revisto a cada três anos), não se fazendo uso de sistema apostilado.

A escola emprega cinquenta funcionários, dos quais 38 docentes. Os demais se distribuem entre as funções de coordenação pedagógica, secretaria, portaria, cantina, monitoria e serviço de limpeza. Por ser uma empresa de pequeno porte, a gestão dos recursos humanos é marcada pela multifuncionalidade. Além das proprietárias, que extrapolam suas atribuições oficiais, exercendo atividades diversas, os profissionais contratados também se revezam no exercício dos cargos:

Elas [as proprietárias] vão aproveitando os profissionais... mais de uma função, mas eles são contratados por tantas horas. Então, dentro dessas tantas horas, eles podem fazer várias atividades. Por exemplo, o motorista de uma van, na hora do recreio, olha o nosso recreio (coordenadora pedagógica).

As quatro irmãs proprietárias dividem entre si as funções estratégicas da escola: Conceição é diretora, Ruth é vice-diretora (e responsável pela reprografia), Clara é coordenadora pedagógica e Inês é secretária. Mas essa divisão do trabalho não é rígida, flexibilizando-se conforme a conjuntura. Durante a pesquisa de campo, Clara, por exemplo, ocupava também o lugar de uma professora que estava em licença maternidade. Com relação ao processo de tomada de decisões, são as quatro irmãs, em conjunto, que deliberam os rumos da instituição. Segundo os entrevistados, elas buscam ter ciência de tudo e não se posicionam sobre temas críticos sem reunir todas as sócias. 0 resultado é uma gestão ponderada e centralizada na família proprietária: “elas não casaram e vivem em função dos alunos, só isso [...] [vivem] só para a escola”, como afırma a coordenadora do EM.

Há ainda dois irmãos que não são proprietários, mas que trabalham na instituição: Francisco auxilia nas reformas do prédio, como informa a coordenadora: "Elas têm um irmão que é aposentado do São Judas Tadeu. Ele mexia com isso lá. Então tudo o que precisa aqui ele tá fazendo". E outra irmã que é responsável pela cantina e cujo marido acumula duas funções: motorista de uma das vans e monitor de informática. 
0 caráter familiar da instituição agrada sobremaneira aos pais que estimam que isso propicia um ambiente mais acolhedor para os filhos: "É uma escola família. Eu vejo que a escola [José] tem uma acolhida. Elas são cinco irmãs que são proprietárias da escola [...] eu vejo a escola [José] não só como um colégio, é um ambiente familiar" (mãe de três alunos: um do EF e duas do EM).

$\mathrm{E}$ um atendimento mais personalizado às famílias:

[Se] Não dá pra vir nas reuniões... elas me recebem em horas diferentes, é só eu ligar e marcar. $\mathrm{Ou}$, às vezes que eu não podia sair de todo jeito porque estava trabalhando muito no dia, à noite elas mandavam pra mim por telefone, explicavam o assunto que estava acontecendo. Então pra mim sempre foi bom. Elas têm esse contato mais próximo com a gente (mãe de aluna do EM).

Esse último aspecto é destacado em oposição ao que se supõe ocorrer nas escolas públicas e, até mesmo, nas grandes escolas privadas. Angélica, a coordenadora do ensino fundamental (séries finais) e do ensino médio, declara utilizar o aplicativo de celular WhatsApp para manter contato permanente com pais, e com especialistas que eventualmente atendem os alunos fora do âmbito da escola.

Além disso, duas outras características da escola José agradam particularmente aos pais: o clima disciplinar reinante e a segurança que oferece aos alunos, em contraposição ao que supõem ocorrer na escola pública.

Dentre todas as características da Escola José, a ênfase na disciplina no ambiente escolar talvez seja a mais destacada, o que ficou evidenciado durante o trabalho de observação in loco. No recreio, poucos alunos correm pelo espaço escolar, provavelmente também em razão da inexistência de área externa. Mas, ainda assim, a escola se vale de monitores e de um porteiro/inspetor/disciplinário (que é ex-policial) responsável por manter a ordem. A proprietária (e secretária) Inês revela aspectos do modus operandi que assegura a manutenção de um clima escolar tão ordeiro:

No recreio tem o Ilton que é o inspetor. Além do Ilton, em cada parte da escola tem um monitor que fica próximo dos banheiros. A gente até orienta: "põe uma menina [uma monitora do sexo feminino] próximo do banheiro das meninas, no caso dela precisar entrar lá, ela entra". Então, os recreios são: cada andar fica um monitor, tem cinco monitores, com o Ilton seis, cada andar tem um monitor, dois, acompanhando.

0 mesmo se pode dizer em relação ao sentimento de segurança que envolve a comunidade escolar. A preocupação constante em evitar os fenômenos de violência e de drogas, levou a direção a instalar câmeras na fachada externa ("E quando a porta está fechada, elas [proprietárias] controlam lá embaixo" coordenadora) e a garantir a presença constante de disciplinários dentro da instituição.

Também, o transporte escolar, por meio de vans da própria escola, é visto pelas famílias como um fator de grande segurança, além da comodidade para aqueles que residem a maior distância.

A Escola José recebe alunos de instituições privadas (de pequeno porte) do entorno, especialmente para ingresso no ensino médio, uma vez que apenas duas instituições privadas oferecem EM na região. Uma delas está situada na mesma rua e a menos de cem metros de distância da Escola José. Dentre as escolas privadas do município de Contagem, essa última instituição ficou à frente da Escola José, no ranking do Enem 2015. Em relação às escolas públicas do entorno, as proprietárias citam três principais fontes de alunos, todas muito próximas geograficamente: duas escolas municipais que distam cerca de 1.500 metros, e uma terceira que fica a trezentos metros da instituição. Nenhuma delas oferece EM e todas 
apresentam Ideb inferior à média do município, o que parece endossar a hipótese de Camelo (2014) acima mencionada. De acordo com uma das proprietárias, a cada novo pedido de matrícula, a escola busca dados sobre o passado escolar do candidato, chegando a ligar para a direção da escola de origem, em certas situações. No caso de candidatos provenientes de escola privada, há a preocupação com a adimplência da família.

\section{A Escola Maria}

Adaptada a partir da residência onde, por longos anos, viveu sua proprietária, a Escola Maria se confunde com uma moradia familiar. Seus aspectos materiais e a relação entre os atores trazem a marca de um ambiente doméstico e informal. 0 próprio espaço físico da instituição era compartilhado, inicialmente, entre a família e o negócio familiar, o que contribuiu para imprimir uma aparência pouco convencional à escola.

Andressa é a proprietária e diretora da escola. Filha de um torneiro mecânico e de uma dona de casa, ambos com escolaridade inferior ao atual ensino fundamental, Andressa logrou chegar ao ensino superior, cursado paralelamente ao trabalho como gestora do estabelecimento.

A escola foi criada em 1987 no imóvel que, à época, era a residência dos pais de Andressa e onde ela foi criada. No início das atividades, seus pais ainda moravam ali: a escola ocupava o andar inferior e a família residia no segundo piso. Pouco a pouco, Andressa começou a realizar alterações no espaço físico para atender às necessidades de ampliação da escola. Ambientes foram divididos e outros construídos; parte do quintal foi transformada em quadra e, assim, a casa foi sendo adaptada aos poucos às finalidades do empreendimento. Após a morte do pai, Andressa e suas duas irmãs, Adriana e Andréia, compraram um apartamento para moradia da mãe, em troca da utilização gratuita de todo o imóvel como instituição de ensino.
0 pai da Andressa, depois cedeu aqui, né? Essa parte de baixo... que ele morava em cima [...]. Sempre foi com a ajuda do pai... da mãe que ela trabalhou. As irmãs dela estão sempre aqui juntas (cantineira e porteira).

Durante a primeira década, a instituição atendeu apenas a crianças de três a seis anos que cursavam a educação infantil. Em 1998, a partir da demanda das famílias, as séries iniciais do ensino fundamental começaram a ser implementadas de forma gradual. Nessa época, Andressa decidiu substituir o nome da instituição (considerado muito infantil), pelo nome atual, uma homenagem à sua própria mãe $e^{7}$ Em 2002, as séries finais do EF também começaram a ser ofertadas gradativamente, a pedido da clientela. Atualmente, a Escola Maria oferece o ensino infantil e fundamental completos e conta, no total, com 158 alunos, divididos em turmas de aproximadamente quinze alunos.

ApesardeAndressaseraúnica proprietária e administradora do estabelecimento, suas irmãs acabaram se filiando ao negócio e hoje trabalham na instituição, dividindo responsabilidades com ela. Adriana é professora de inglês aposentada e se afastou da escola por motivo de doença, mas Andréia continua ativa e ocupa uma posição de "quase vice-diretora", nos termos de Andressa, embora sua função oficial seja de secretária e responsável pela educação integral no período do contraturno. A filha de Andressa também integra o corpo de funcionários da escola. Formada em direito e estudante de geografia no momento da pesquisa, Tábata leciona geografia, inglês e colabora com a mãe em diversas atividades da instituição. Assim, além de sediada em espaço físico semirresidencial, a Escola Maria é também comandada por uma família.

Agora essa [irmã] que está aqui dentro foi professora de inglês, está aposentada [...].

\footnotetext{
7- Daí nossa escolha pelo nome fictício de Escola Maria
} 
Aquela outra [irmã] que você viu chegando lá é secretaria da escola e de manhã fica no integral, fazendo para casa e tudo. E a filha da Andressa é professora de geografia e inglês à tarde (cantineira e porteira).

Se não houvesse uma grande placa, na fachada, com o nome da Escola Maria, sinalizando que naquele local funciona um estabelecimento de ensino, seria difícil imaginar que aquela casa abriga uma escola, pois, ainda hoje, a construção tem ares de residência familiar.

Imagem 11 - Fachada da Escola Maria.

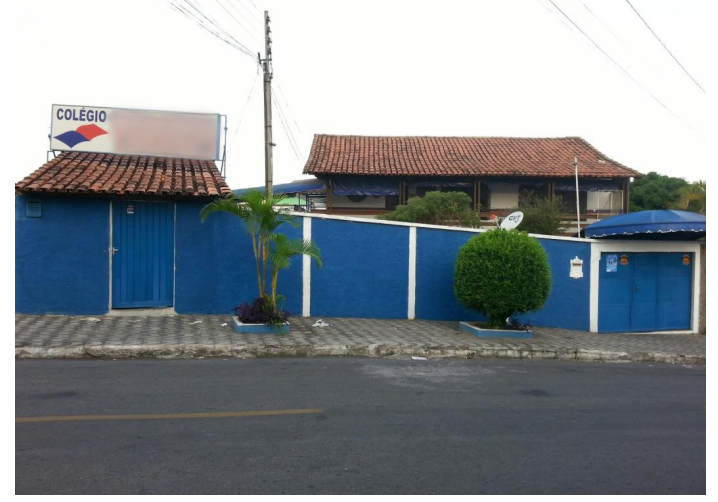

Fonte: arquivo pessoal da pesquisadora.

Mesmo após passar pelo grande portão de ferro, o aspecto é de uma moradia. Um pequeno jardim acolhe o visitante e uma escada leva até a recepção que dá acesso à sala da diretoria/sala dos professores. No primeiro piso, há também salas de aula, construídas ao longo do tempo, que podem ser acessadas passando pela quadra. Ainda no térreo, em outra edificação, está localizada a cantina. No segundo andar, situamse salas de aula, biblioteca/sala de vídeo e um pequeno refeitório. Acima da cantina, há uma sala que dá acesso à saída de alunos. Entre as duas edificações, no piso superior, uma ponte de ferro foi construída para garantir a circulação.

A Imagem 13 permite dimensionar a extensão total do terreno em cujo centro se situa a quadra usada para recreio de todos os alunos (incluído o ensino infantil que não possui pátio próprio) e para as aulas de educação física do EF I.

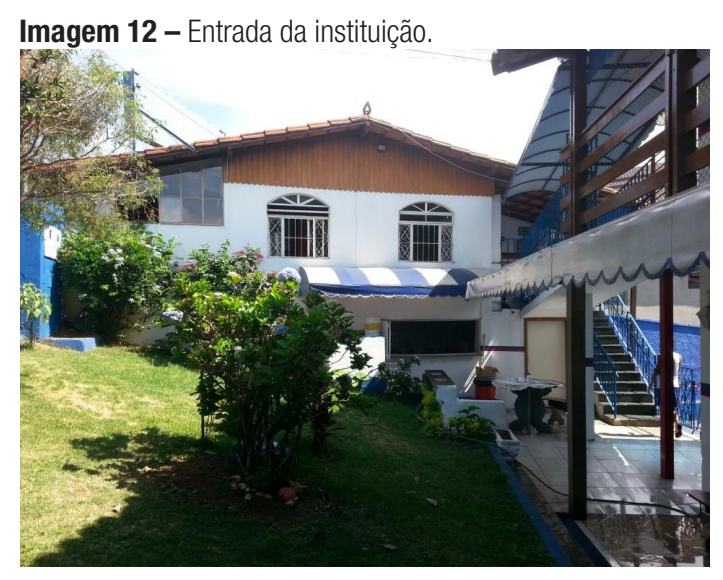

Fonte: arquivo pessoal da pesquisadora.

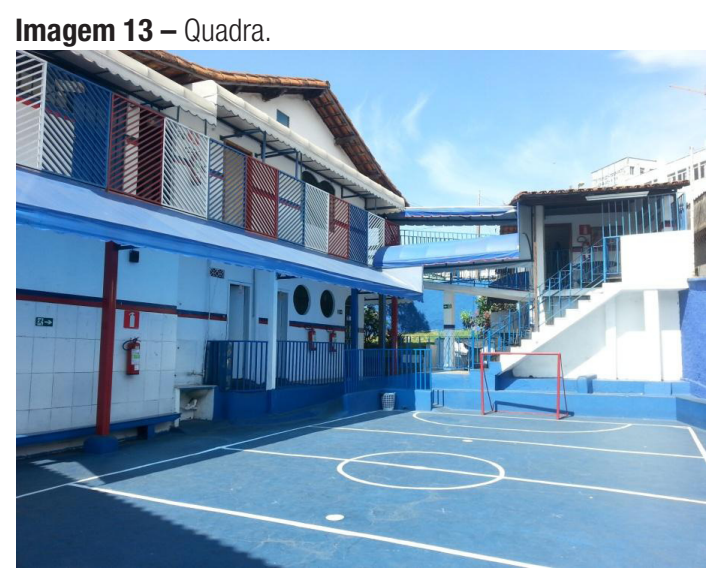

Fonte: arquivo pessoal da pesquisadora.

A feição familiar também pode ser constatada nos móveis da recepção que aparenta uma sala de estar com sofás e objetos decorativos típicos de um domicílio.

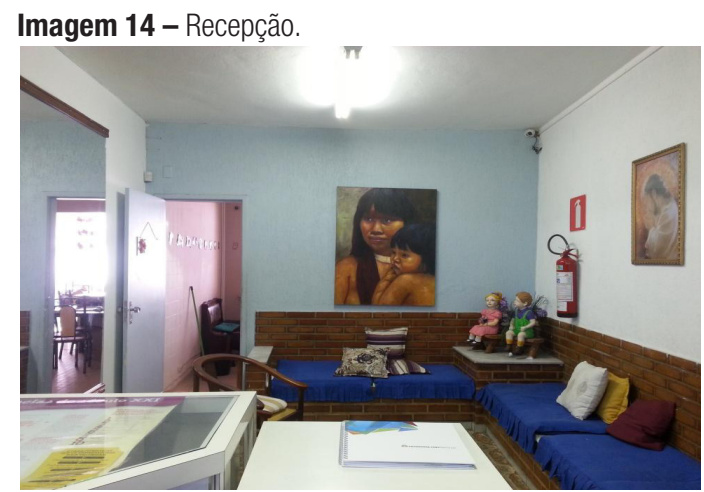

Fonte: arquivo pessoal da pesquisadora. 
A Imagem 15 exibe um aparelho de som numa estante da recepção da escola, um eletrodoméstico pouco comum nesses ambientes. A presença de imagens religiosas contradiz a natureza declaradamente laica da escola. Durante a pesquisa de campo, foram observadas professoras rezando a oração do Pai-Nosso dentro de sala de aula.

\section{Imagem 15 - Imagens religiosas.}

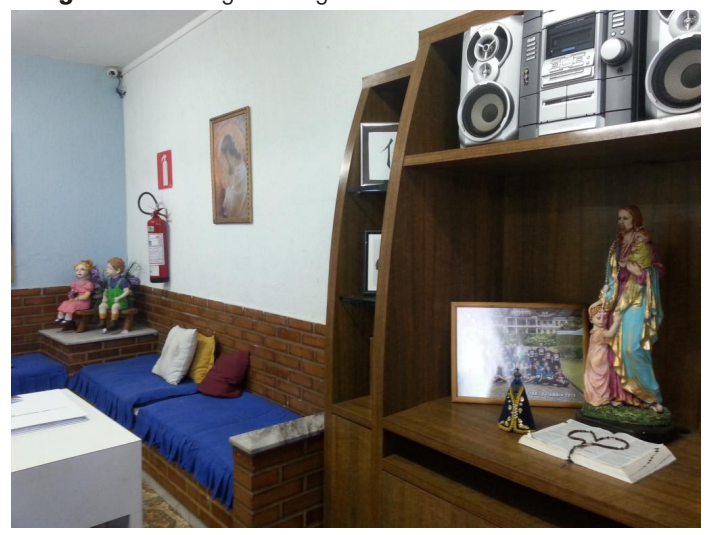

Fonte: arquivo pessoal da pesquisadora.

Na sala de aula, constata-se o número reduzido de carteiras. A cadeira do professor é um móvel assemelhado a cadeiras de cozinha de domicílios, o que, mais uma vez, evidencia que a instituição foi equipada com objetos remanescentes de um passado residencial.

\section{Imagem 16 - Sala de aula.}

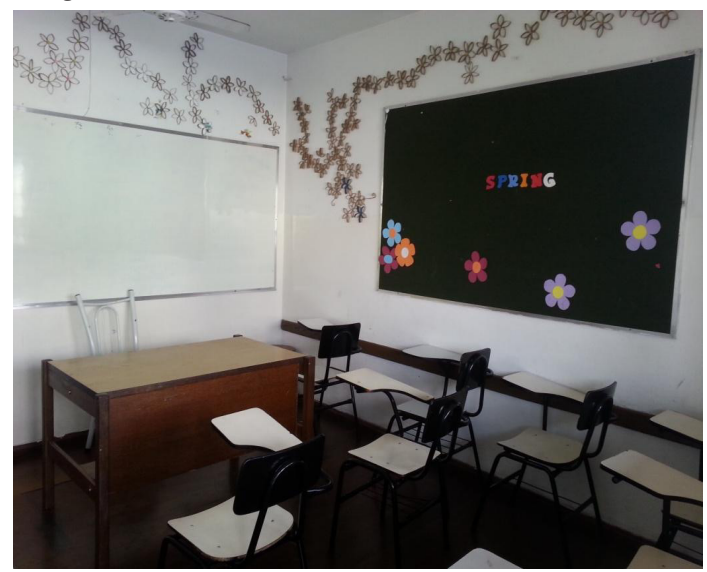

Fonte: arquivo pessoal da pesquisadora.
A biblioteca da Escola Maria, com seu reduzido número de livros, revela baixo investimento nesse equipamento, paralelamente à constatação, por parte da direção, da preferência dos alunos por leituras virtuais. É, no entanto, ali que os alunos do período integral permanecem no contraturno. A sala também possui uma televisão, à esquerda ${ }^{8}$, que representa uma opção de entretenimento para os estudantes que terminam suas tarefas escolares.

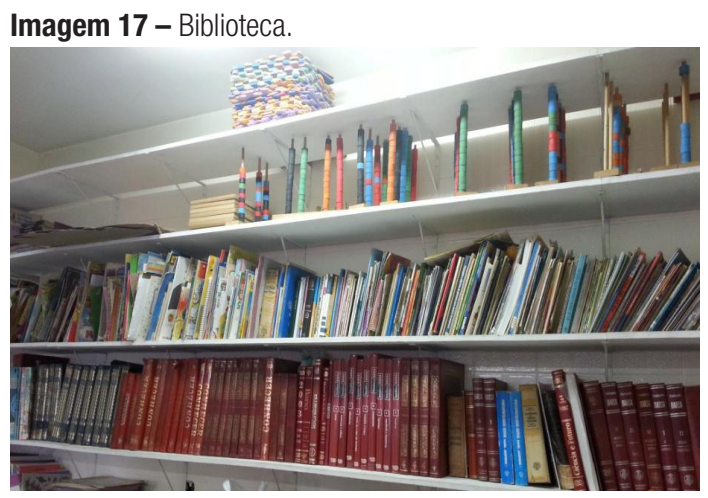

Fonte: arquivo pessoal da pesquisadora.

As imagens apresentadas não deixam dúvidas sobre as dimensões diminutas do espaço físico com que conta a Escola Maria. Os corredores laterais, externos à edificação, sinalizam uma casa que foi se modificando ao longo do tempo, improvisando soluções para permitir a circulação de pessoas. Como não há escada interna, toda a passagem entre os pisos é feita pela escada visível nas fotografias. A entrada para as salas de aula é feita a partir do exterior das edificações, de forma a eliminar corredores internos e melhor aproveitar o espaço. A quadra é o único espaço de lazer dos alunos.

Esse fato levou a proprietária a buscar algumas soluções fora do ambiente escolar. Fez, por exemplo, uma parceria com um clube próximo, onde se realizam as atividades de educação física dos alunos das séries finais do EF. A festa junina e as formaturas também acontecem fora da instituição, em espaços maiores.

8- A TV não pode ser vista porque a foto foi cortada a pedido da direção, alegando que a prateleira de baixo estava desarrumada. 
Do ponto de vista da infraestrutura pedagógica, a instituição também encontra desafios. A escola não possui datashow. Quando o professor precisa fazer uso deste tipo de equipamento, é necessário que ele traga de casa. Em relação ao laboratório de ciências, a escola também encontrou dificuldades em renovar o material pedagógico e Andressa acabou abrindo mão desse ambiente.

Alguns equipamentos não puderam ser repostos ao longo dos anos, e hoje a escola usa do improviso para não perder a qualidade. No caso da sala de informática, foi impossível, economicamente, acompanhar o ritmo acelerado da mudança tecnológica:

Nós tínhamos [sala de informática]. Só que à tarde substituí a aula de informática por música. E de manhã por mais uma aula de espanhol. Na realidade, nós fomos uma das primeiras escolas que adquirimos computadores. Foi uma compra que fiquei apertadíssima. Adquiri seis computadores. Tínhamos a aula de informática e tudo mais. Só que com o passar do tempo, sai computador novo toda semana, todo mês. Nossos equipamentos ficaram defasados. Os meninos tinham [em casa] computadores muito mais possantes. Depois vieram celulares, tablets, notebooks, que aí nós não colocamos mesmo. Ai eles fazem [aulas de informática] fora mesmo, quando querem. (Andressa, proprietária).

Porém, a infraestrutura acanhada não parece se constituir em problema para os pais. Essa é a opinião de Priscila, mãe de dois alunos do EF, que confessa que a escola pequena foi um atrativo para ela e a compara a uma aula particular:

[Escolhi] por ser uma escola pequena, tem poucos alunos, a chance de ter uma atenção maior dos professores é grande. Não tem espaço para brincar não, mas por ter um melhor acompanhamento dos professores... É como se fosse uma aula particular mesmo. De
10, 15 alunos, no máximo [...]. Pra mim isso [a estrutura física] não tem tanta importância. Pra mim eles estão aqui pra aprender a ler e escrever, a ter uma boa educação.

A prática pedagógica da Escola Maria não se define por uma concepção teórica predeterminada. A proprietária confessa aderir a uma metodologia mais tradicional, com a frequente adoção de aulas expositivas. Contudo, admite que o número reduzido de alunos por turma facilita o desenvolvimento de atividades pedagógicas baseadas no diálogo. 0 material didático é constituído principalmente de livros, pois, segundo ela, o sistema de apostilas engessa o trabalho do professor.

Ao chegar à Escola Maria, a pesquisadora se depara com uma situação inusitada. Andressa, sempre muito elegante e maquiada desde as primeiras horas da manhã, está descalça, com a barra da calça dobrada sobre os joelhos, vassoura na mão, aproveitando a água da piscina de armação - que havia sido esvaziada - para lavar a quadra da escola. Essa cena descreve bem a proprietária da instituição. Andressa chega antes das seis da manhã e é a última a sair da escola. Durante o dia, executa as mais variadas tarefas, muitas delas simultaneamente, e está sempre à disposição de todos que a procuram. A proprietária tem domínio e conhecimento dos pormenores da instituição que administra há 29 anos, incluindo a clientela, os educadores e as atividades desenvolvidas. A própria Andressa fornece detalhes da multifuncionalidade que marca sua gestão:

Eu sou dirigente da instituição. Porém eu faço todo trabalho que for necessário. Vou para sala de aula. E minha formação é em pedagogia e psicologia. Então, assim, atendo os alunos, converso, e assim, eu não estou naquele local. Supervisiono pedagogicamente, eu faço de tudo um pouco. De manhã, eu tô sem secretária, então eu sou secretária e dirigente. E à tarde que eu tenho a secretária. Escola 
pequena hoje fica difícil você gerir uma instituição com muitos funcionários. Então todo mundo abarca várias funções.

Embora Andressa centralize as decisões da instituição, os profissionais que a cercam têm uma trajetória antiga na casa e, por isso, segundo a proprietária, têm os valores da instituição introjetados, não carecendo de supervisão constante. Além dos dezessete professores, Andressa conta com três funcionários: sua irmã, Andréia, que é secretária e está na escola desde o início, e duas cantineiras/porteiras/ faxineiras que trabalham na Escola Maria há dezessete e vinte anos respectivamente. Assim como Andressa, os demais funcionários desempenham múltiplas funções.

Vários são os aspectos que evidenciam o caráter familiar impresso na gestão da escola: do nome da instituição aos vínculos familiares que unem seus agentes, passando pelas características do espaço físico. Para Andressa, a gestão familiar traz confiança e união para o trabalho cotidiano. Ela espera que essa situação se prolongue por meio da decisão (desejada) da filha de dar prosseguimento ao empreendimento da família.

Uma característica destacada da Escola Maria é o atendimento personalizado aos alunos e às famílias. Essa atenção individual ocorre tanto em sala de aula como nos demais ambientes do estabelecimento de ensino, o que seria um diferencial da instituição:

Eu não marco para atender pai. A hora que ele chega ele vai ser atendido. Eu posso estar fazendo o que for. Se você chegar aqui e falar: Andressa, eu quero falar da minha filha, se eu tiver no telefone eu vou falar: "espera um minuto" [...]. Aquele problema seu vai ser resolvido agora. Por mais banal que seja. Pode ser a tampinha da garrafa da sua filha que sumiu [...]. Você não sai daqui sem a gente ter um leque de possibilidades e ter aquilo resolvido em poucos dias, não sai! Seja uma blusa sumida, seja um problema de para-casa com um professor, Eu não deixo o pai sair daqui sem atender. (Andressa, proprietária).

Os sujeitos entrevistados utilizam frequentemente expressões como segunda casa ou escola familiar, para descrever a atmosfera da instituição. De fato, trata-se de um estabelecimento de ensino onde os alunos parecem estar à vontade, sem, contudo, perder de vista a ordem. A postura de permanente atenção com que cercam os alunos não impede a vigilância disciplinar. Andressa relata como conquistou a disciplina dos alunos com sua atitude de acolhimento:

Eu considero uma escola amiga mesmo. Essa postura, esse autoritarismo, até já tentei, algumas vezes, mudar esse... sabe? E ficar uma pessoa mais severa, mais brava, assim com o semblante mais... com uma distância maior, para eu testar. Mas não sinto que fluiu. Eu sinto que... às vezes eu sinto uma disciplina maior por ter uma pessoa que eles podem contar, e eles não quererem me ofender. "Eu não vou fazer isso com a Andressa, eu não vou fazer isso com o professor". Eu sinto que dá mais certo. (Andressa, proprietária).

Um dispositivo intitulado diário de bordo é o mais importante recurso utilizado no controle da disciplina. Nele, nove itens são listados para conferência dentro da sala de aula, a saber: dever de casa não realizado; dever de casa incompleto; comportamento; uniforme; conversa; não apagou o livro didático $^{9}$; não trouxe o material; não trouxe atividade avaliativa; falta de respeito. Ao final da aula, o diário de bordo é recolhido pela própria Andressa que toma as atitudes cabíveis de acordo com a infração. Há sempre uma conversa com o aluno, mas, caso seja necessário, a diretora faz contato com os pais.

\footnotetext{
9- Do sexto ao nono ano do EF, o livro didático é reaproveitado.
} 
A segurança dos alunos constitui outra grande preocupação da direção, expressa, por exemplo, em outra cena observada na Escola Maria. Ao final da aula do período vespertino, a porteira se posiciona no portão de saída da escola com um microfone na mão. Conforme os pais vão chegando para buscar os filhos, ela chama o aluno pelo nome, e só então a saída dele é permitida. A escola também instalou câmeras no exterior do imóvel para garantir o controle:

A Andressa é muito assim, com relação a isso ela é muito preocupada, então, assim, ela colocou câmera, instalou câmera, não tinha não, ela instalou agora, o portão sempre mantém fechado, a gente olha quem é mesmo, procura saber quem é, pra liberar menino a gente não libera, se for pra pessoa que a gente não conheça não é liberado de forma alguma, tanto que já avisa pro pai, se vier outra pessoa buscar, ou você liga, manda um bilhete ou manda a carteirinha do aluno com a foto da pessoa que vai vim buscar, tá? (professora do $5^{\circ}$ ano do ensino fundamental).

Mas há que se reconhecer que o número reduzido de alunos facilita tanto o controle disciplinar como a segurança dos alunos.

A Escola Maria figura em um mercado escolar constituído por escolas privadas do entorno, e com mensalidades muito próximas àquela praticada pela Escola Maria. Há ainda dois estabelecimentos públicos situados a menos de 1.500 metros de distância, um municipal e outro estadual que representam, ambos, potenciais concorrentes da Escola Maria. Prova disso é a declaração da proprietária Andressa de que há um trânsito de alunos que se dá entre todas essas instituições públicas e as privadas. Como a escola não oferece o ensino médio, Andressa destaca instituições federais de prestígio e duas escolas do sistema $\mathrm{S}$ como destinos principais de seus alunos, ao final do ensino fundamental. Curiosamente, a diretora não cita a Escola José, apesar de ter sido apontada pela direção dessa última como fonte de alunado para seu EM. Talvez porque as instituições por ela citadas estejam à frente da Escola José nos rankings do Enem, valorizando assim a instituição de que é proprietária.

\section{Conclusão}

A indagação central que perpassou todo este texto deriva do fenômeno atual de expansão de um segmento específico da rede privada de ensino, e se refere às características de que se revestem os estabelecimentos escolares que emergem ou se multiplicam nesse novo cenário. Para tanto, focalizamos duas escolas privadas da região metropolitana de Belo Horizonte que passaram, na década de 2000 , por um claro processo de crescimento da matrícula e dos serviços ofertados.

Da perspectiva investigada, os dados examinados revelaram que as duas escolas apresentam, entre si, muito mais elementos comuns do que diferenças, embora seja possível identificar algumas dissemelhanças entre elas. No que convergem fundamentalmente?

Em primeiríssimo lugar em sua gênese marcada pela história de duas famílias que, de origem social modesta, precisaram reunir esforços e, até mesmo, apoio externo (de um grande e tradicional colégio particular da região e da própria família) para levar a cabo o empreendimento sonhado. E essa origem familiar terá repercussões em mais de um plano.

Originalmente instaladas em imóveis residenciais, elas foram passando, aos poucos, por adaptações funcionais às finalidades de uma instituição de ensino e aos imperativos do crescimento de seu corpo discente. Em permanente processo de construção, por meio do que coloquialmente poderíamos chamar de puxadinhos, as edificações foram sendo modeladas ao longo do tempo, por meio da construção de novas salas, da divisão de ambientes, enfım, da montagem de estruturas a partir do prédio original. Mas, ainda hoje, seu espaço físico conserva nitidamente os resquícios de uma origem domiciliar.

Porém, aquilo que poderia ser considerado um ponto fraco se erige, paradoxalmente, em 
um de seus maiores atrativos: serem vistas, por seus usuários, como uma segunda casa ou como uma escola familiar, onde a comunicação intensa e permanente com os pais os convida a acompanhar cada detalhe do que sucede com seus filhos no interior do estabelecimento, aspecto enfatizado pela grande maioria dos educadores e, sobretudo, das famílias que declaram ser este um dos motivos principais de sua opção pela instituição, a despeito de reconhecerem a falta de espaços para lazer e sociabilidade dos alunos.

Graças ao reduzido número de alunos, os educadores e demais funcionários dizem ter condição de conhecer bem a clientela, identificando todos pelo nome, e garantindo um clima mais acolhedor. Ambas as escolas se dispõem a receber os pais com prontidão e em horários flexíveis, curvando-se às necessidades individuais e, até mesmo, utilizando novas redes sociais - como o aplicativo WhatsApp para alimentar o contato. Em síntese, a gênese familiar dessas escolas se faz presente em todos os seus aspectos, a começar pelo próprio nome da instituição.

E é em função da infraestrutura e das condições materiais que as práticas pedagógicas são desenvolvidas. Isso significa que não há uma estratégia pedagógica definida a priori, mas sim a busca da melhor forma de explorar, para fins educativos, os recursos disponíveis. Daí decorrem os improvisos verificados durante a pesquisa de campo, os quais constituem a resposta criativa dos atores para fazer face às limitações. Isso fica evidente, por exemplo, na Escola Maria, quando um professor traz de casa seu próprio aparelho de datashow; e na Escola José, por ocasião da transformação temporária em auditório, de um espaço destinado à circulação de pessoas.

Do ponto de vista dos recursos humanos, essa característica de improvisação se reflete na relativa multifuncionalidade que marca o cotidiano de trabalho dos funcionários que se dividem entre diferentes funções. No entanto, a gestão dos estabelecimentos evidencia a forte presença das famílias proprietárias, com as decisões concentradas no núcleo familiar que constitui a peça-chave da administração da instituição.

O clima bastante disciplinado e de observância das regras representa outro aspecto essencial dessas instituições, como já havia sido destacado no estudo de Nogueira (2013b) sobre os critérios de escolha da escola privada por famílias da chamada nova classe média ${ }^{10}$. Nelas impera um controle sistemático da frequência, da pontualidade, do uso do uniforme, da proibição de celulares ${ }^{11}$ e, last but not least, da ordem em sala de aula. Nesse quesito, as duas instituições se distinguem apenas no modus operandi de que se servem para atingir essas metas: enquanto a Escola José ostenta práticas mais rígidas de vigilância, a Escola Maria adota procedimentos de maior flexibilidade e escuta dos alunos que ela supõe incentivar a aceitação das regras, e até das punições, em casos de transgressão.

A segurança dos alunos é outra forte preocupação das escolas pesquisadas. Munidas de câmeras externas e internas, e de funcionários altamente incumbidos do acompanhamento permanente dos alunos ("ficar de olho", nas palavras de uma mãe), as escolas pretendem representar um contraponto às acusações constantes de ameaça à integridade física dos alunos de que a escola pública é alvo. 0 fato do disciplinário e porteiro da Escola José ser um ex-policial é bem visto e parece confortar pais e educadores.

Essas escolas estão situadas em um mercado escolar formado por instituições públicas e privadas de ensino, mas elas configuram, sem dúvida, pontos de referência para as famílias da região, em suas comparações no que tange a questões relativas à disciplina, segurança ou qualidade do ensino. De fato, os depoimentos das proprietárias/diretoras dos dois estabelecimentos de ensino pesquisados

10- A tese central da autora é a de que essas famílias evitam a escola pública, sobretudo em razão da indisciplina e insegurança que supõem nela reina.

11- Chama a atenção, por exemplo, sua capacidade de controle do uso do celular, que constitui, atualmente, um desafio imposto aos estabelecimentos de ensino, em geral. 
dão conta de um movimento, nos últimos anos, de vai e vem de alunos entre suas instituições e as escolas públicas do entorno. Com efeito, no ano de 2016, a crise econômica afetou ambas as instituições com um conjunto de alunos migrando para a rede pública. Por outro lado, no início de 2017, uma greve no sistema municipal de ensino de Contagem desencadeou o movimento oposto, gerando aumento de matrículas de alunos originários de escolas públicas, além do retorno de algumas famílias que conseguiram superar as dificuldades econômicas do ano anterior. Esse movimento de zapping (cf. LANGOUET; LÉGER, 1991) se associa ao grande empenho das famílias para proteger a escolarização dos filhos das ameaças decorrentes dos momentos de turbulência financeira, evitando ao máximo a necessidade de recorrer ao ensino público e gratuito. Já, em relação à circulação apenas entre os estabelecimentos privados, o trânsito se dá mais em função de inadaptações, mudanças de endereço ou outros problemas de natureza particular.

Em função desse contexto, essas instituições parecem ter consciência de que - em termos mercadológicos - seu mais forte concorrente é a escola pública, pois frequentemente se definem em relação, ou melhor, em oposição a ela. 0 mesmo ocorre no discurso dos pais que, em sua grande maioria, associam sua opção pela escola particular à imagem negativa que fazem da escola pública, não disfarçando sua firme intenção de evitá-la, como também mostram as pesquisas de Fernandes (2008), Iório (2013), Perosa e colaboradores (2015), Nogueira (2013b), Camelo (2014). Se essa tese estiver correta, a prosperidade desse segmento da rede privada de ensino composto por escolas de custo mais baixo - estaria relacionada, para além de seus atributos próprios, ao processo de descrédito que assola a escola pública brasileira.

\section{Referências}

CAMELO, Rafael. A educação privada em São Paulo: expansão e perspectivas. São Paulo: Fundação Seade, 2014. (1ª análise; n. 19).

FERNANDES, Fatima Denise Peixoto. Da "educação para poucos" à "educação para todos": a fragilização da imagem da escola pública. 2008. 119f. Dissertação (Mestrado em Educação) - Universidade Federal do Estado do Rio de Janeiro. Rio de Janeiro, 2008. Disponível em: <http://educacao.unirio.br/index.php?page=defendidas-em-2008>. Acesso em: 14 nov. 2015.

IÓRIO, Angela Cristina Fortes. Socialização profissional na sala de professores: um retrato do trabalho docente num colégio de rede privada do subúrbio carioca. In: REUNIÃO NACIONAL DA ANPEd, 36., 2013, Goiânia. Anais... Goiânia: ANPEd, 2013. p. 1-17.

LANGOUET, Gabriel, LÉGER, Alain. Public ou privé? Trajectoires et réussites scolaires. La Garenne-Colombes: Publidix/Espace Europén, 1991.

MEDEIROS, Jonas, JANUÁRIO, Adriano. A nova classe trabalhadora e a expansão da escola privada nas periferias da cidade de São Paulo. In: REUNIÃO NACIONAL DA ANPOCS, 38., 2014. Anais... Caxambu. Caxambu: Anpocs, 2014. p. 1-30

NOGUEIRA, Maria Alice. A "nova classe média" brasileira e a escolarização dos filhos: escolha do estabelecimento de ensino e mercado escolar. Belo Horizonte: UFMG, 2013a. Projeto de pesquisa.

NOGUEIRA, Maria Alice. No fio da navalha: a (nova) classe média brasileira e sua opção pela escola particular. In: ROMANELLI, Geraldo; NOGUEIRA, Maria Alice; ZAGO, Nadir. Família \& escola: novas perspectivas de análise. Petrópolis: Vozes, 2013b. p. 109-130.

PEROSA, Graziela Serroni et al. Transformations des classes populaires et de l'offre scolaire à São Paulo. Brésil(s). Sciences Humaines et Sociales, n. 8, p. 7-31, nov. 2015. Disponível em: <http://bresils.revues.org/1612>. Acesso em: 26 jul. 2017. 
SIQUEIRA. Ana Rita. Um segmento menos elitizado da rede privada de ensino: três escolas no município de Contagem. 2016. Dissertação (Mestrado em Educação) - Faculdade de Educação da Universidade Federal de Minas Gerais. Belo Horizonte, 2016.

Recebido em: 16.03 .2017

Modificações em: 07.07.2017

Aprovado em: 19.07.2017

Ana Rita Siqueira é psicóloga, mestre em educação pela Universidade Federal de Minas Gerais (UFMG) e coordenadora de apoio escolar da Rede de Colégios Santa Maria.

Maria Alice Nogueira é doutora em ciências da educação pela Universidade de Paris V. É professora titular da Faculdade de Educação da Universidade Federal de Minas Gerais (UFMG), onde criou e coordenou o Observatório Sociológico FamíliaEscola (OSFE). 